\title{
Errata
}

\section{Advanced glycation end-products: a review}

\author{
R.Singh, A. Barden, T. Mori, L. Beilin \\ Department of Medicine, University of Western Australia and West Australian Heart Reseach Institute, Perth, Australia
}

Diabetologia (2001) 44: 129-146

Aminoguanidine does not cleave advanced glycation end-product induced protein cross-links. In fact, it may inhibit the formation of such cross-links.

- Page 130, paragraph 7, line 6 should read: “. .which could inhibit AGE-induced chemical cross-link formation. ."

- Page 140, paragraph 6, line 2-3, where it should read: "... .and could inhibit cross-link formation (Table 2). ."

- Table 2, under the Method of action heading, line 2 it should read: "could inhibit cross-link formation"
These statements are all supported by the references that follow them, in particular references:

20. Vlassara H (1996) AGE's and atherosclerosis. Ann Med 28: 419-426

143. Giardino I, Fard AK, Hatchell DL, Brownlee M (1998) Aminguanidine inhibits reactive oxygen species formation, lipid peroxidation and oxidant induced apoptosis. Diabetes 47: 1114-1120

145. Nilsson BO (1999) Biological effects of aminoguanidine: an update. Inflammation Research 48: 509-515

\section{Diabetes mellitus and the stomach}

\section{G. Stacher}

Psychophysiology Unit, Department of Surgery, University of Vienna, Vienna, Austria

\section{Diabetologia (2001) 44: 1080-1093}

References have been missed (indicated in bold) in the first sentence on page 1081, left column and should read as follows: "Since diabetic patients' feelings of early satiety and postprandial epigastric full- ness were first attributed to delayed gastric emptying [1], the latter disorder was found to prevail in 30 to $60 \%$ of individuals with Type I (insulin-dependent) diabetes mellitus $[4-9, \mathbf{1 1}, \mathbf{1 3}, \mathbf{1 5}]$ and with Type II (non-insulin-dependent) diabetes mellitus $[7,10, \mathbf{1 2}$, 14]."

G. Stacher, Psychophysiology Unit, Department of Surgery, University of Vienna, Vienna, Austria, e-mail: georg.stacher@ akh-wien.ac.at 